\title{
Les cellules souches
}

Stem cells

\section{MOTS-CLEFS : \\ - Cellules souches, tissu gingival, \\ tissu osseux, \\ tissu musculaire, \\ régénération, ingénierie tissulaire, fonctions.}

\section{KEYWORDS:}

- Stem cells, gingival tissue, bone tissue, muscle tissue, regeneration, tissue engineering, functions

\section{Résumé}

Chez l'Homme, au stade du bouton embryonnaire, dans certaines conditions, les cellules de ce dernier peuvent se différencier en toutes cellules constituant un organisme : elles sont dites totipotentes. Chez l'adulte, une sub-population de cellules participe, in vivo, à l'homéostasie de chacun des tissus constitutifs du territoire oro-facial et se différencie en cellules spécifiques dans chacun de ces tissus. Ces cellules reçoivent le nom de cellules souches pluripotentes.

Des recherches actuelles sont entreprises, in vitro et in vivo, pour exploiter le potentiel thérapeutique des cellules souches. Dans le domaine oro-facial, ces cellules sont présentes dans les tissus, ò disposition du praticien et peuvent être utilisées comme agent régénérateur.

\section{Abstract}

In humans, the cells at the embryonic disk stage can, under certain conditions, differentiate into all types of cells in the body: such cells are totipotent. In adults, a subpopulation of cells participates in in vivo homeostasis of each of the tissues forming the orofacial zone and gives rise to cells specific for each tissue type. These cells are known as pluripotent stem cells.

Research is currently under way both in vitro and in vivo to explore and exploit the therapeutic potential of stem cells. In the orofacial zone, these cells are present in tissues, accessible to the practitioner and can be used for regenerative therapies.
AOS 2014;268:4-15

DOI: $10.1051 / \mathrm{aos} / 2014202$

(C) EDP Sciences 2014

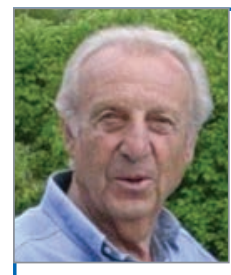

- Roland BENOÎT, Docteur en Chirurgie Dentaire, Dr DSO, Dr d'Etat, HDR, assistant chercheur au laboratoire d'Histologie. Embryologie Paris V 1969-1971, Chercheur au Muséum d'Histoire Naturelle et au laboratoire de Biologie et des biomatériaux du milieu buccal 1971-1991. Professeur d'Orthopédie-Dento-Faciale Paris V 1971-1994. Membre de l'Académie de Chirurgie Dentaire. Président de la commission Recherche. Membre SFODF, EOS, EOL, IADR.

\section{Librairie Garancière}

Retrouvez le livre "De la face au visage» ard du Pr Benoît sur : www.librairie-garanciere.com ou flashez ici :

DE LAFACE AU VISAGE 

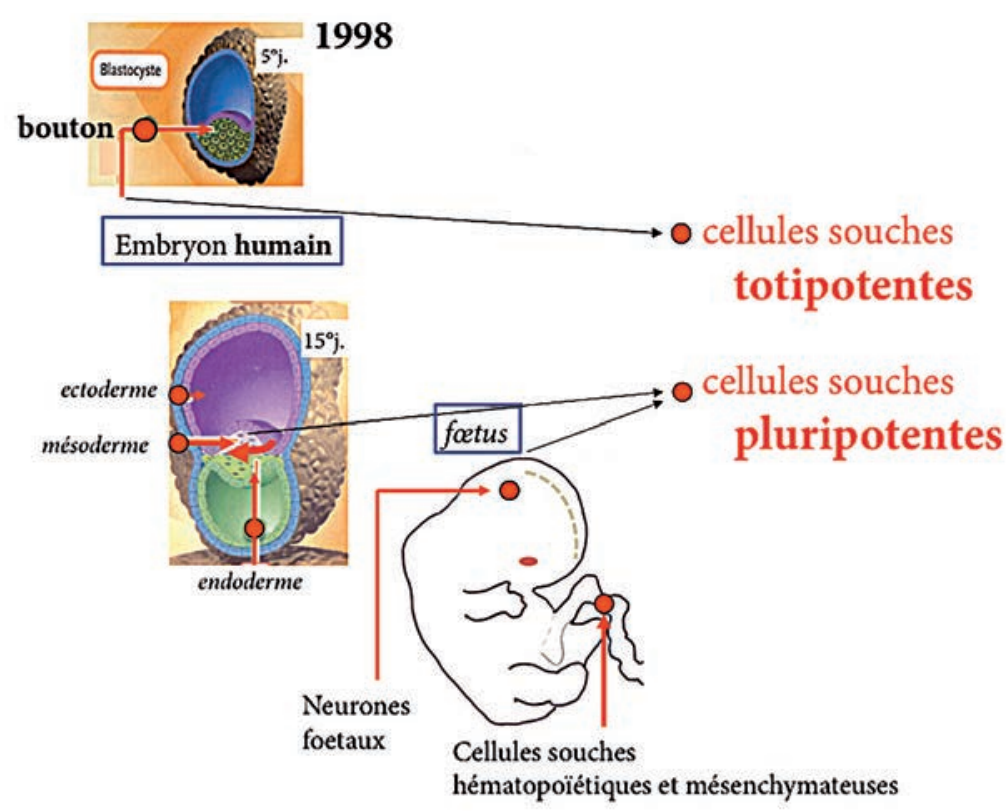

Les cellules souches sont présentes dans la crête neurale native et sont pluripotentes

$\Delta$ Fig. 1.

Cellules souches embryonnaires.

\section{CELLULES SOUCHES EMBRYONNAIRES}

Actuellement, les cellules souches embryonnaires proviennent d'embryons conçus par fécondation in vitro, et ne faisant pas l'objet d'un projet. Les cellules, provenant d'un bouton embryonnaire, sont aptes à se différencier en toutes les différentes cellules de l'organisme humain, comme les neurones, les cellules du sang, les cellules osseuses ou musculaires. On dit alors qu'elles sont totipotentes car elles peuvent reconstituer un organisme complet. Après un développement de 15 jours, les cellules embryonnaires ont encore de larges possibilités : elles sont dites pluripotentes. Plus tard, chez le foetus, les cellules des crêtes neurales, les neurones, celles du cordon ombilical et du sang restent pluripotentes [14]. Ainsi, les cellules du sang fotal peuvent être à l'origine de toutes les cellules sanguines, en particulier des cellules hématopoïétiques et des cellules souches mésenchymateuses (CSM) (fig. 1).

\section{CELLULES SOUCHES DE L'ADULTE}

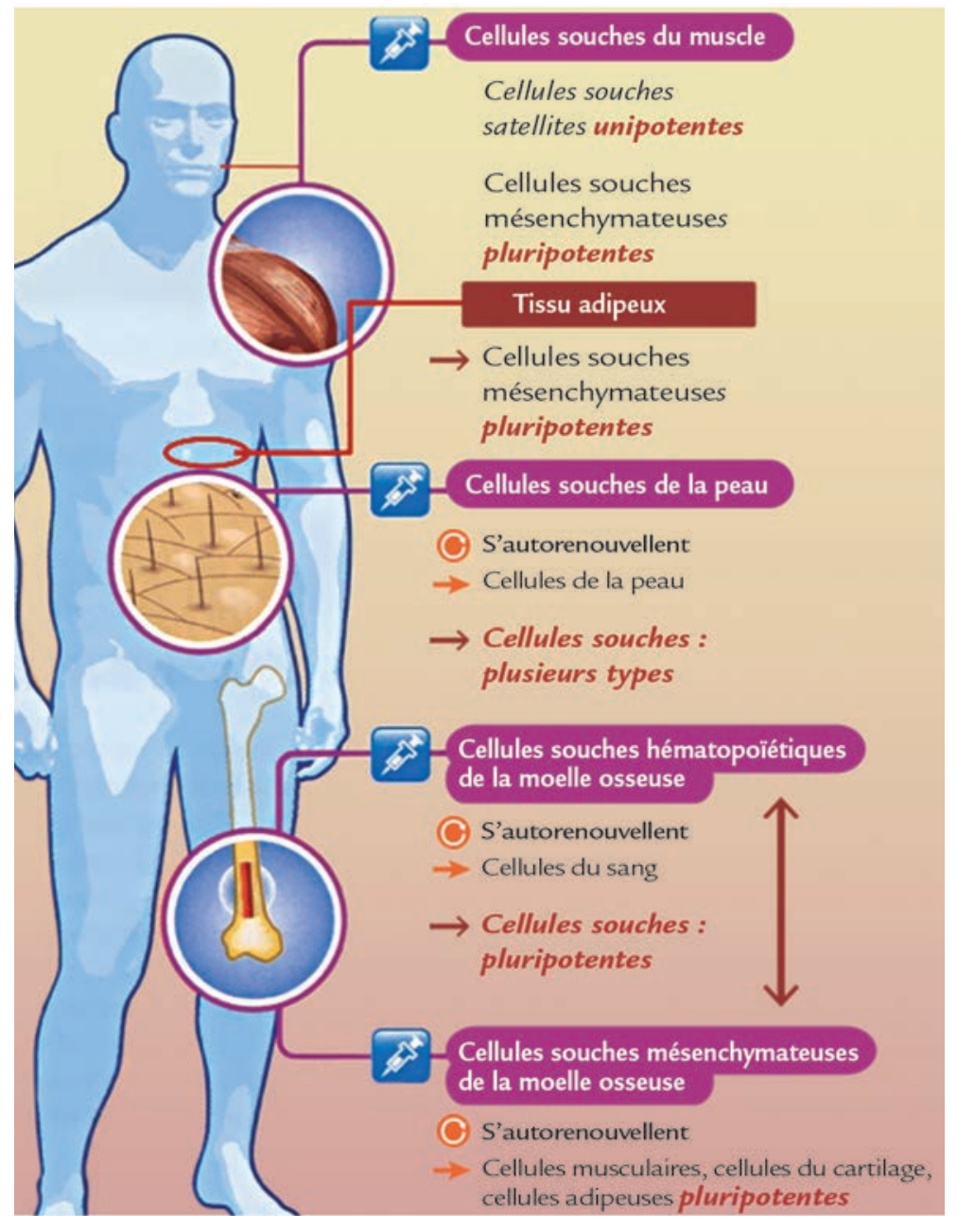

$\Delta$ Fig. 2.

Cellules souches adultes.
Les cellules souches participent au fonctionnement des divers tissus dont elles assurent l'homéostasie. Chaque tissu renferme un stock de cellules qui a gardé les caractères des cellules embryonnaires dont elles dérivent. On peut comprendre que les organes formés à partir du mésoderme possèdent des cellules mésenchymateuses aptes, en fonction de leur environnement, par l'intermédiaire de messages chimiques, à produire des progéniteurs de fibroblastes pour le muscle lisse, le muscle strié, le cartilage, l'os et le tissu adipeux. Il existe, actuellement, des marqueurs spécifiques qui peuvent reconnaître, malgré leur faible nombre, les cellules souches dans ces divers tissus [10]. Les cellules souches du cerveau. Dans cet organe, formé à partir de l'ectoderme, les cellules souches neurales endogènes permettent de régénérer des neurones fonctionnels dans les zones lésées. Ceci laisse supposer une thérapie cellulaire neuronale [17]. Dans ces différents tissus, les cellules souches ont des qualités différentes, soit unipotentes, soit pluripotentes (fig. 2).

\section{CELLULES SOUCHES IPS (INDUCED PLURIPOTENT STEM CELLS)}

\section{Cellules souches IPS in vitro}

Une recherche dans un milieu de culture approprié (4 gènes spécifiques de reprogrammation) a réussi, à partir de cellules indifférenciées (cellules de peau 


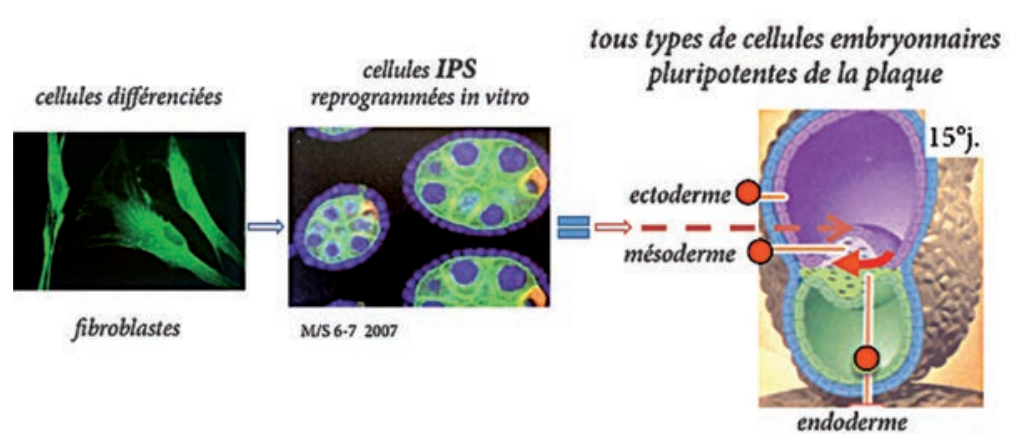

$\Delta$ Fig. 3.

Cellules différenciées reprogrammées en cellules pluripotentes : IPS.

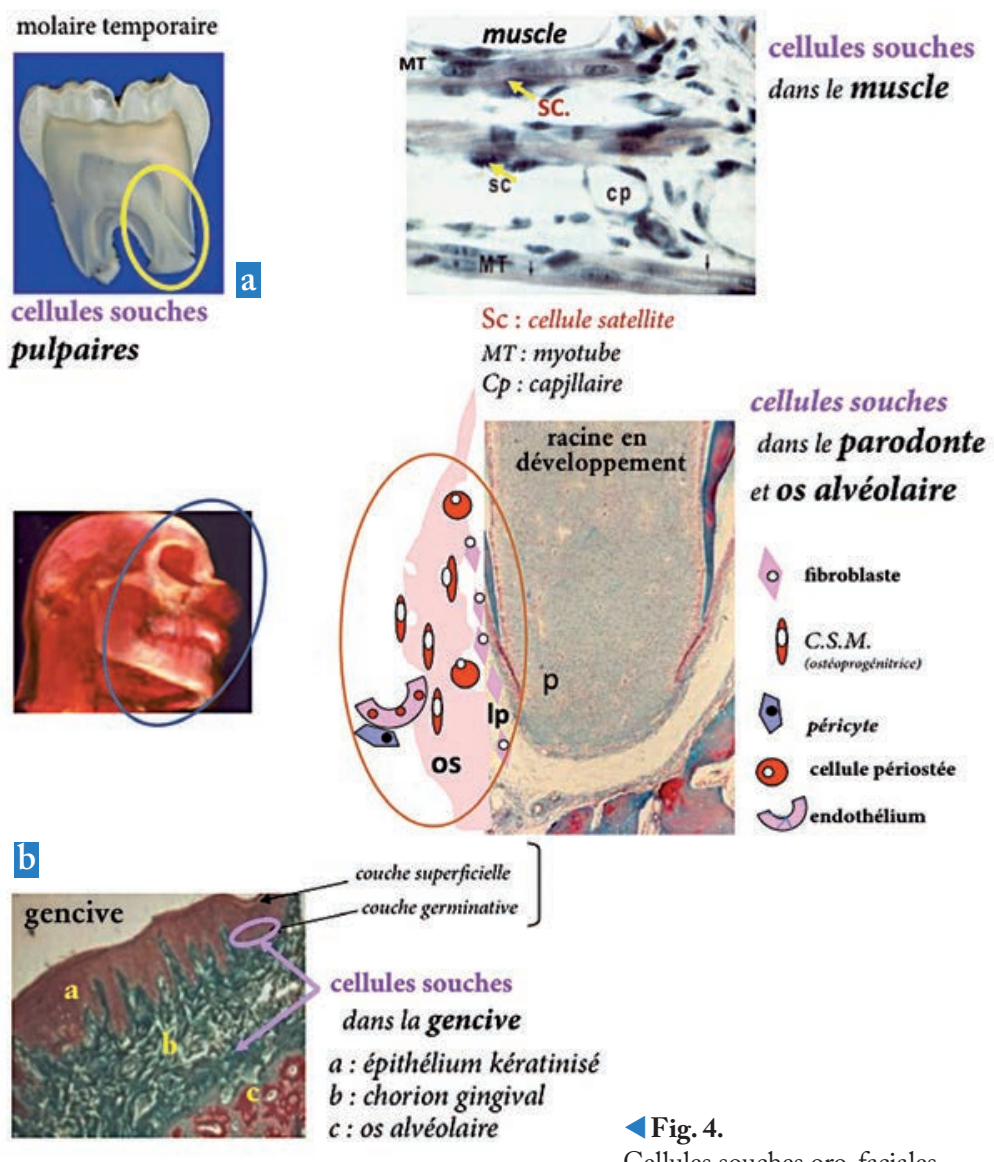

Cellules souches oro-faciales.

cellules souches de la pulpe dentaire et de la partie apicale

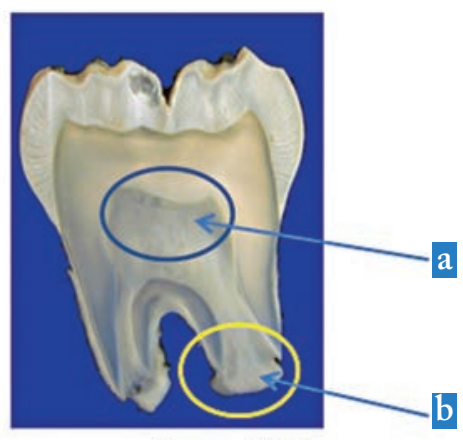

dent exfoliée

$\Delta$ Fig. 5.

Cellules souches pulpaires.

de souris), à obtenir des cellules souches pluripotentes [6]. Ces cellules possèdent la capacité d'être à l'origine de tous les types de cellules de l'organisme (fig. 3, 4).

\section{Cellules souches IPS reprogrammées in vivo}

Une équipe espagnole [1] marque une nouvelle étape dans l'exploration du potentiel des cellules IPS. Ces chercheurs ont reprogrammé, in vivo, chez la souris, des cellules souches en modifiant génétiquement cet animal.

Note: les cellules souches pluripotentes induites IPS ou les cellules souches présentes dans les tissus peuvent être utilisées, après expérimentation, dans des thérapies cellulaires, comme dans des maladies génétiques et/ou dégénératives.

\section{CELLULES SOUCHES PULPAIRES}

\section{Cellules souches de la pulpe centrale}

Il existe dans la pulpe des dents adultes des cellules souches dormantes (fig. 5a). Elles pourraient être sollicitées à la suite d'une lésion tissulaire et participer à la réparation de la dentine [12, 23]. Cependant, leur différenciation semble limitée.

\section{Cellules souches apicales pulpaires}

Les cellules souches apicales pulpaires se situent dans les dents temporaires humaines exfoliées. Elles prennent le nom de cellules souches mésenchymateuses (CSM). Elles sont caractérisées d'auto-renouvellement d'une pluripotence et d'une fonction immuno-modulatrice [20]. Récemment, une technique de préservation par cryoconservation a été expérimentée avec succès [18]. Ces cellules se caractérisent par une large prolifération, des capacités de pluripotences et de différenciations in vitro en cellules odontoblastiques, ostéoblastiques, adipocytaires et neuronales. D'autre part, in vivo chez la souris, elles se montrent capables de régénérer de nombreux tissus - dentine, moelle osseuse, os de la voûte crânienne, os des maxillaires - et d'agir sur la production de lymphocytes T. Ces cellules (HANGAR) sont donc pluripotentes, destinées à la thérapie cellulaire et à la médecine régénératrice immunitaire.

Depuis que ces cellules souches (HANGAR) ont été identifiées (2003) et les caractères pluripotents démontrés après cryoconservation, la différenciacion a pu être confirmée pour d'autres cellules. Leur pluripotence se révèle pour des cellules endothéliales, neuronales, myocytaires. Déjà elles ont été utilisées en ingénierie tissulaire, in vivo, chez les petits animaux, 


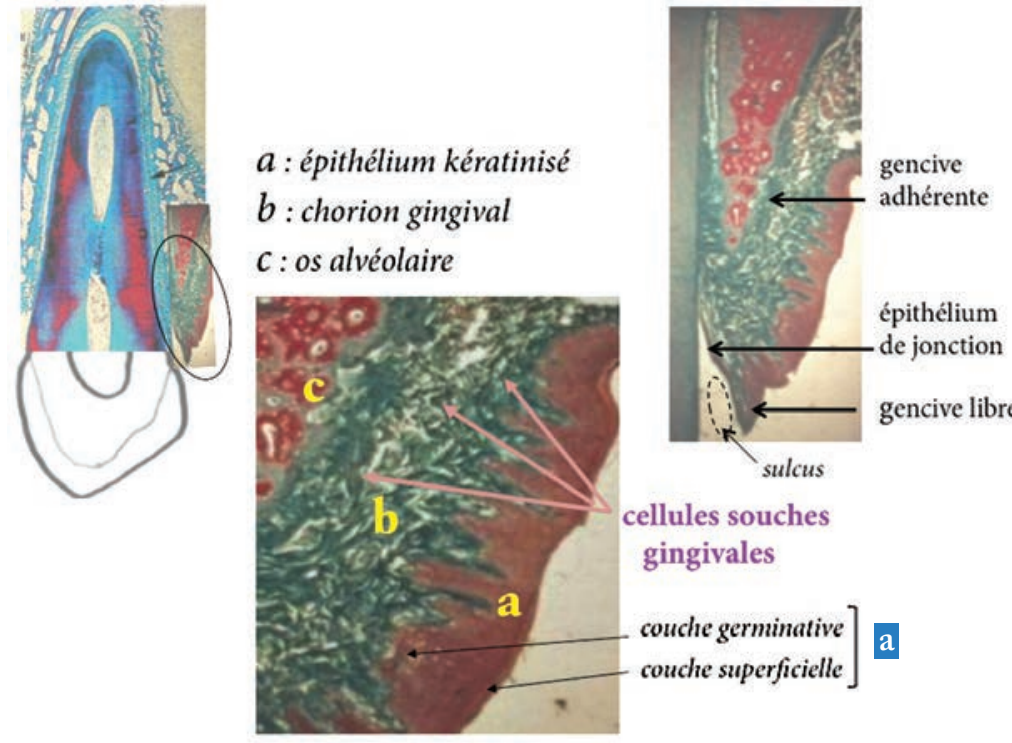

$\Delta$ Fig. 6.

Cellules souches gingivales pluripotentes.

pour des défauts osseux, dans la dystrophie musculaire et les défauts dentinaires. Ces recherches sont un préalable à l'application clinique [15].

\section{CELLULES SOUCHES GINGIVALES}

La gencive est la portion buccale qui recouvre les procès alvéolaires et entoure le collet des dents (fig. 6). Dans la cavité buccale, la gencive, libre et adhérente, a été un tissu protecteur tout au long de l'évolution. Ce tissu gingival a acquis de grandes propriétés de défense et d'auto-renouvellement grâce à son épithélium et à ses cellules souches.

Les cellules souches sont localisées dans la couche germinative de l'épithélium et parmi les fibroblastes du chorion gingival.

\section{Épithélium gingival}

L'épithélium gingival pluristratifié qui revêt le chorion gingival est une barrière de protection physique et anti-infectieuse (fig. 6). Les cellules épithéliales agressées sont alors soumises à un intense renouvellement. Celui-ci est assuré par les cellules souches de la couche germinative (fig. 6a). Dans cette situation, le tissu épithélial ne peut se développer et subsister que s'il interagit avec le derme sous-jacent. Le système de défense est différent dans l'épithélium de recouvrement et dans lépithélium de jonction. Ce dernier se multiplie beaucoup plus rapidement que l'épithélium gingival car il possède une protéine Slpi (Secretory Leucocyte Protease Inbibitor) produite sous l'effet de 5 gènes particuliers, dans une quantité 100 fois supérieure à celle trouvée dans l'épithélium gingival, ce qui lui fournit une importante défense immunitaire [13]. Le système de défense est donc différent dans l'épithélium de recouvrement et dans l'épithélium de jonction.

\section{Chorion gingival}

Le conjonctif gingival a une grande capacité de réparation face aux diverses agressions thermiques, chimiques, bactériennes et mécaniques. Cette qualité est acquise depuis la vie embryonnaire et subsiste chez l'adulte grâce à une vascularisation bien assurée et à ses fibroblastes, cellules très abondantes dans ce tissu conjonctif (fig. 6) [9, 11].

Dans les tissus conjonctifs postnataux, comme celui donnant naissance à l'os, à la peau, à la muqueuse buccale, une variété de cellules souches à phénotype différent (MSCs) a pu être isolée comme celle trouvée dans la pulpe, le ligament parodontal, la moelle. La population de fibroblastes gingivaux est hétérogène de par son origine: des fibroblastes ont une origine mésodermique pour la plupart, et un petit nombre provient des cellules des crêtes neurales (CCN). L'ensemble de ces cellules contribue au développement et à la maintenance de ce tissu conjonctif [10]. Les cellules gingivales adultes sont facilement accessibles dans un but d'expérimentation. Elles possèdent certaines caractéristiques, du fait de leur origine (CCN) et leur potentialité de différenciation sont pluripotentes. Elles peuvent être à l'origine de cémentoblastes, fibroblastes ligamentaires, ostéoblastes, chondroblastes. En outre, elles possèdent des propriétés immuno-modulatrices. Ces cellules sont susceptibles d'être largement utilisées en médecine régénératrice.

Aujourd'hui déjà, du fait de ces caractéristiques, le clinicien peut les solliciter dans certaines situations et obtenir une régénération tissulaire, in situ.

Chez cette patiente de 28 ans, le parodonte superficiel est très réduit autour d'un nombre important de dents (fig. 7, 8, 9, 10,11). Ces atteintes tissulaires résultent de tractions répétées des freins et des insertions musculaires péri-buccales lors de la mastication et de la déglutition. La correction orthodontique, des champs masticateurs et des champs dento-alvéolaires antérieurs d'incision, a permis la suppression des agressions environnementales (fig. 12,13,14). Les cellules souches gingivales ont reconstitué une grande partie de la gencive attachée, de la gencive libre. Lépithélium de jonction, grâce à son système de défense particulier, s'est reconstitué (fig. 15).

\section{Mécanismes de biologie régénératrice}

1 Les fonctions de mastication et de déglutition ayant été rétablies orthodontiquement par une articulation dento-dentaire physiologique, il se produit une régénération par les cellules souches du tissu gingival et de son épithélium de recouvrement. 


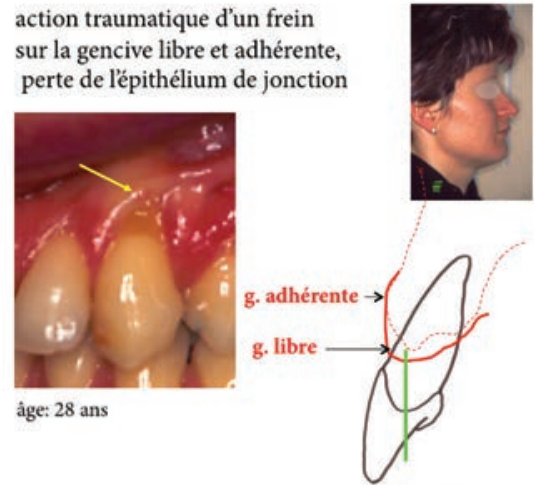

$\Delta$ Fig. 7.

Biologie régénératrice : cellules souches et parodonte superficiel (gencive).
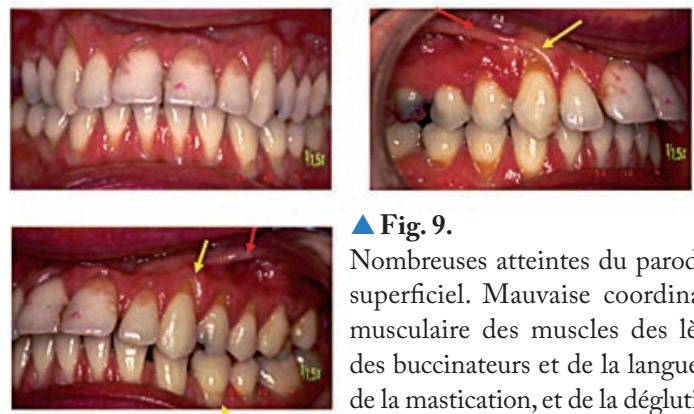

\section{$\Delta$ Fig. 9.}

Nombreuses atteintes du parodonte superficiel. Mauvaise coordination musculaire des muscles des lèvres, des buccinateurs et de la langue lors de la mastication, et de la déglutition.
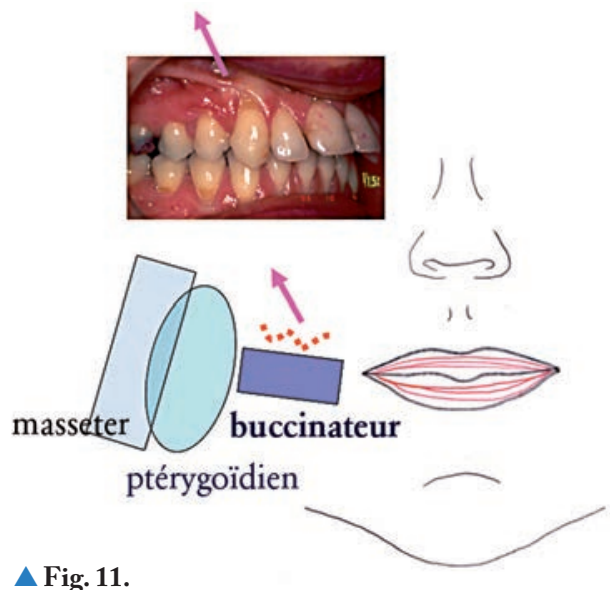

Fig. 11.

Le buccinateur, au contact en arrière avec le ligament ptérygo-maxillaire, par sa fascia, participe aux fonctions de préhension, de mastication et de déglutition. Déséquilibré, il exerce une traction sur la gencive marginale et attachée.

\section{Facteurs environnants : les freins}
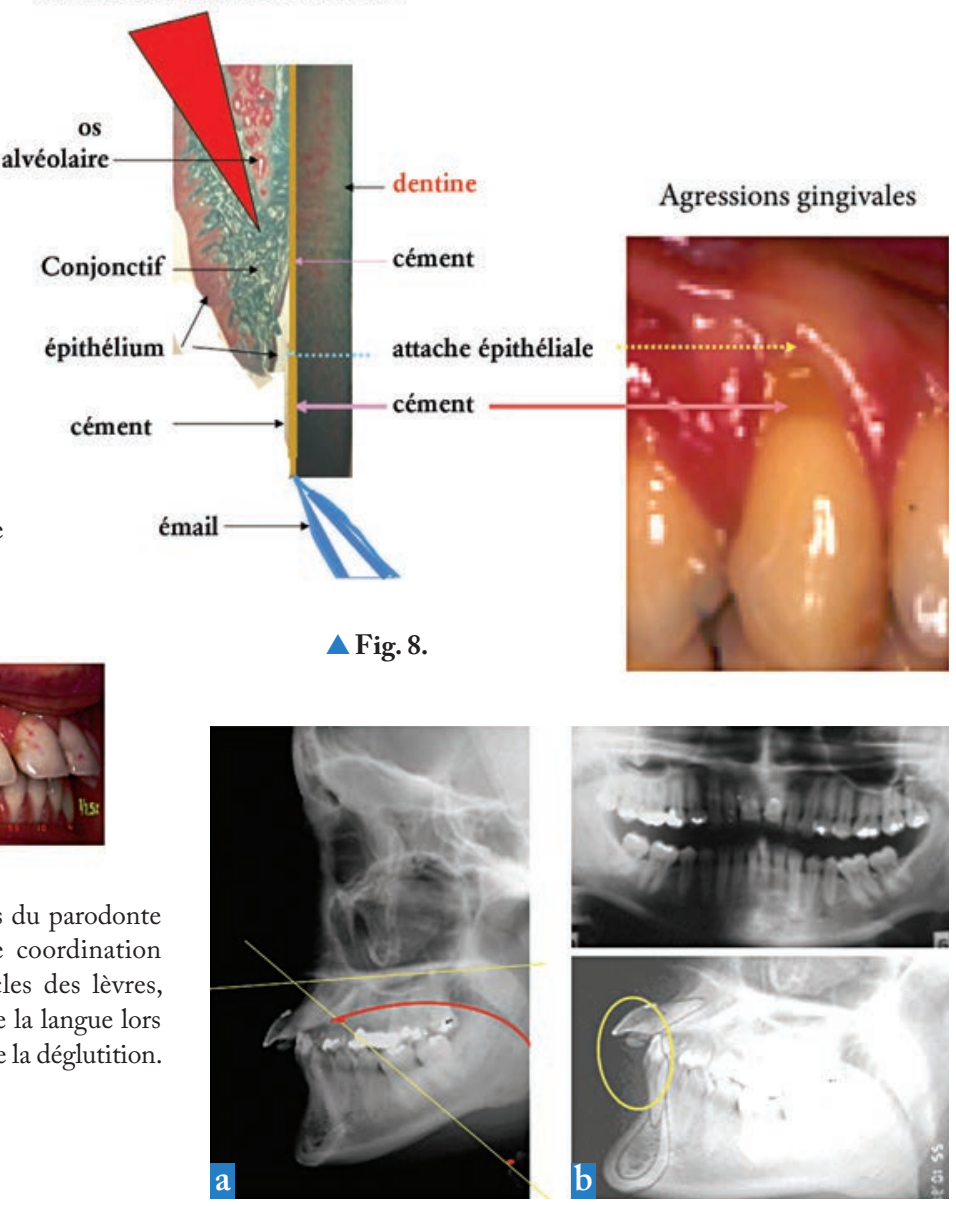

Fig. 10.

Examens complémentaires : classe I squelettique, classe II dentaire. Position anormale de la langue par rapport au palais et à la face linguale des dents (tracé a). La lèvre inférieure s'écrase sur les incisives mandibulaires $(\mathbf{b})$.
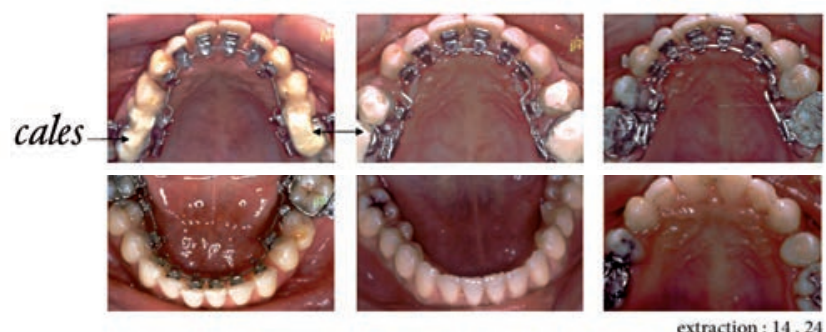

extraction: 14,24

$\Delta$ Fig. 12.

Traitement orthodontique.
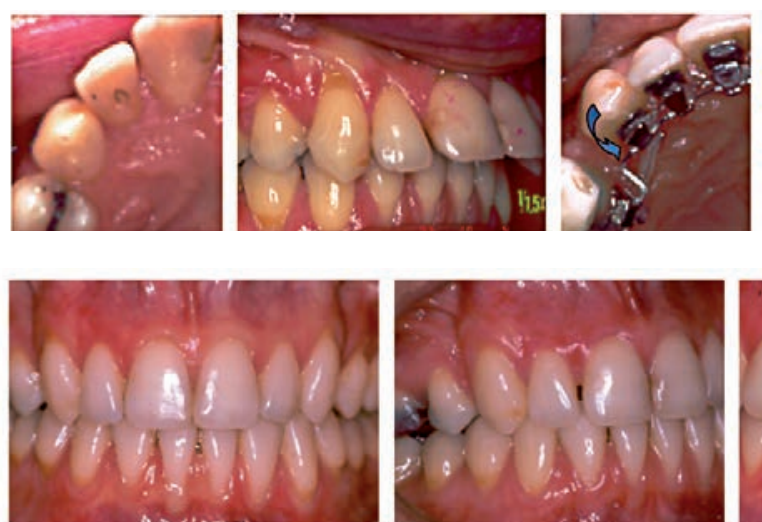

Hygiène ++

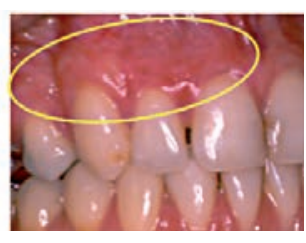

4 Fig. 13.

Biologie régénératrice du parodonte superficiel. Élimination des facteurs environnants (frein et verrou).

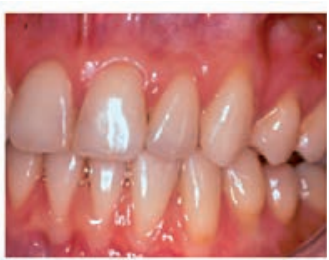

$<$ Fig. 14.

Fin du traitement orthodontique et amélioration du parodonte superficiel. 


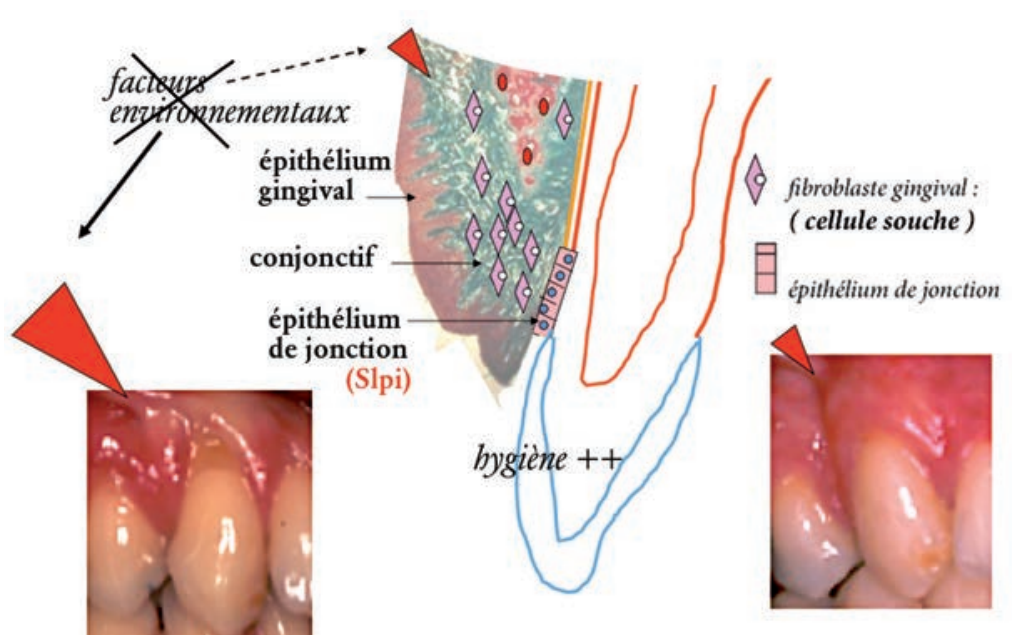

$\Delta$ Fig. 15.

Biologie régénératrice : mécanismes.

\section{Cellules souches disponibles dans los alvéolaire et le ligament parodontal}

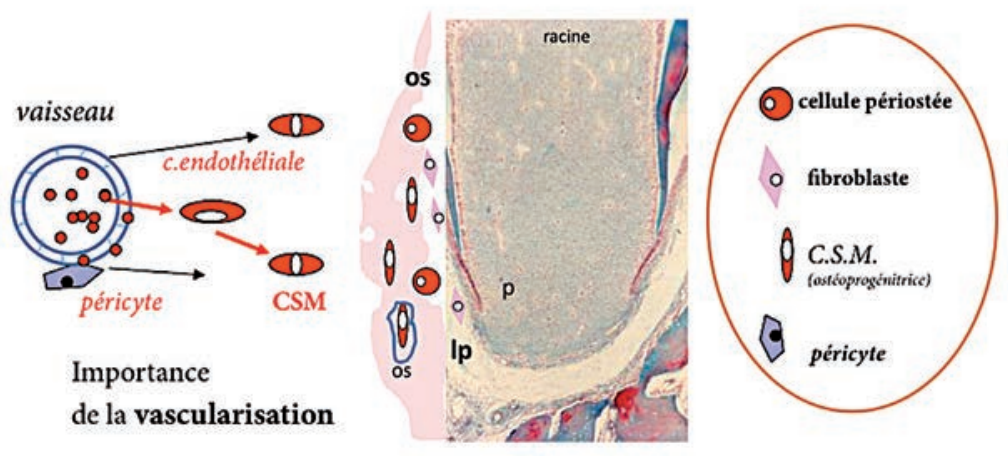

A Fig. 16.

Cellules souches dans le parodonte profond.

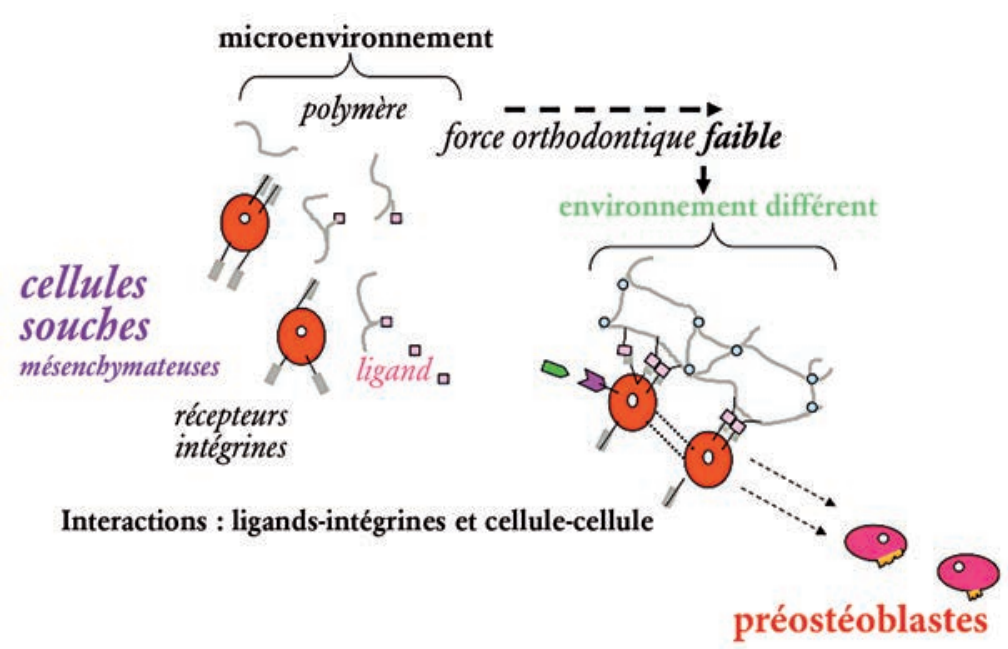

$\Delta$ Fig. 17.

Les C.S.M. (mécano-sensibles) vers une différenciation. Les liaisons ligands-intégrines sont des capteurs de la rigidité de l'environnement (matrice extra-cellulaire) pour une différenciation spécifique ostéoprogénitrice des cellules souches.
I L'épithélium de jonction, à la suite de la suppression de l'environnement négatif et de par ses qualités de défense immunitaire, s'est reconstitué. La fonction de protection est à nouveau rétablie (fig. 15).

\section{CELLULES SOUCHES ET PARODONTE PROFOND}

Dans le parodonte profond, les cellules souches sont présentes parmi les fibroblastes du ligament parodontal, dans le périoste et l'os alvéolaire, dans les espaces médullaires [2,26]. En outre, elles se rencontrent à proximité des vaisseaux, chez les péricytes, dans l'endothélium de ces mêmes vaisseaux et dans le système circulatoire où elles prennent le nom de cellules souches mésenchymateuses (CSM) (fig. 16).

En culture, les cellules souches peuvent se différencier en un grand nombre de cellules spécialisées sous l'influence de facteurs solubles et/ou de facteurs biochimiques dans la matrice extracellulaire. Le facteur de différenciation peut être aussi physique, comme la force de mastication ou la force du déplacement orthodontique.

Ainsi les cellules souches mésenchymateuses sont pluripotentes et peuvent se différencier en cellules ostéoblastiques, chondroblastiques, cémentoblastiques, fibroblastiques, macrophagiques.

Les cellules souches sont capables de répondre à des pressions environnementales différentes. L'engagement des cellules souches vers une différenciation est sous le contrôle d'interactions moléculaires entre les cellules et leur micro-environnement. Les récepteurs membranaires de ces cellules, de type intégrine, interviennent dans ces événements. Une étude récente [3] montre une relation entre les différentes rigidités des matrices extracellulaires et l'engagement ostéogénique des cellules souches mésenchymateuses. On peut penser que, dans le déplacement dentaire provoqué, il est prudent de développer une force légère appropriée pour provoquer la différenciation voulue (fig. 17).

\section{BIOLOGIE RÉGÉNÉRATRICE EXPÉRIMENTALE}

Une expérience, dans le laboratoire de J.L. Saffar (2005, Paris V), met en évidence, chez le rat, le rôle des cellules souches du parodonte de la molaire inférieure après extraction des antagonistes maxillaires. On obtient alors un vrai déplacement physiologique de la molaire qui peut être suivi. Il se produit alors une multiplication cellulaire des cellules souches dans le desmodonte et dans les espaces médullaires de l'os 


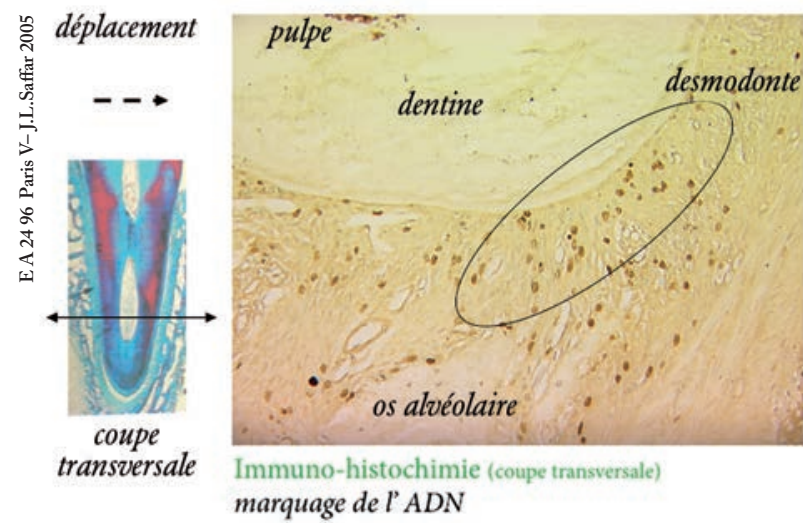

$\Delta$ Fig. 18.

Prolifération cellulaire à l'interface avec la racine (multiplication des CSM) lors d'un déplacement physiologique.

alvéolaire (fig. 18). Après quelques jours, sur coupes histologiques transversales de la racine, on remarque un remaniement tissulaire au niveau du cément et de l'os alvéolaire (marquage fluorescent) (fig. 19).

\section{CAS CLINIQUE}

Le patient de 53 ans est affecté d'une maladie parodontale sévère (fig. 20). Il est tout d'abord traité par un contrôle de plaque, un détartrage sus- et sous-gingival, et une suppression des interférences occlusales. Ce traitement parodontal est suivi d'une chirurgie par lambeau esthétique d'accès et préparation radiculaire optimale (fig. 21).

Au bout d'un mois, le traitement orthodontique consiste en un nivellement de l'arcade mandibulaire par forces légères suivi d'une contention. Sous les mêmes forces, sont ajustés les rapports inter-arcades, statiques et physiologiques (fig. 22, 23). Une contention par crampons métalliques scellés est installée au maxillaire. Après 15 ans, les arcades dentaires sont

$\nabla$ Fig. 20.

Maladie parodontale sévère
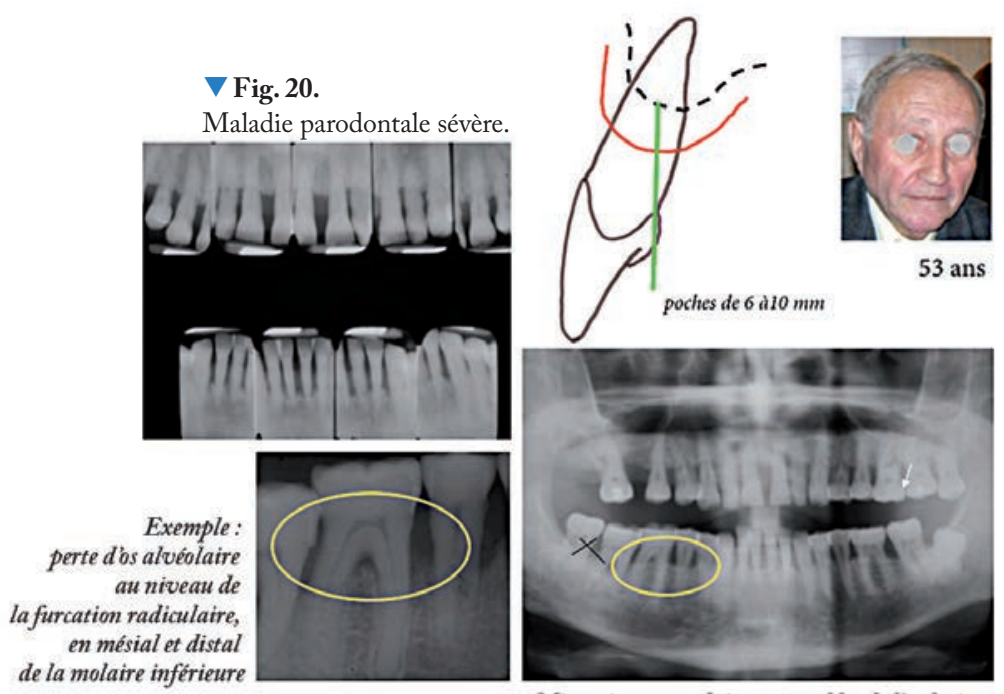

Migrations secondaires et troubles de l'occlusion

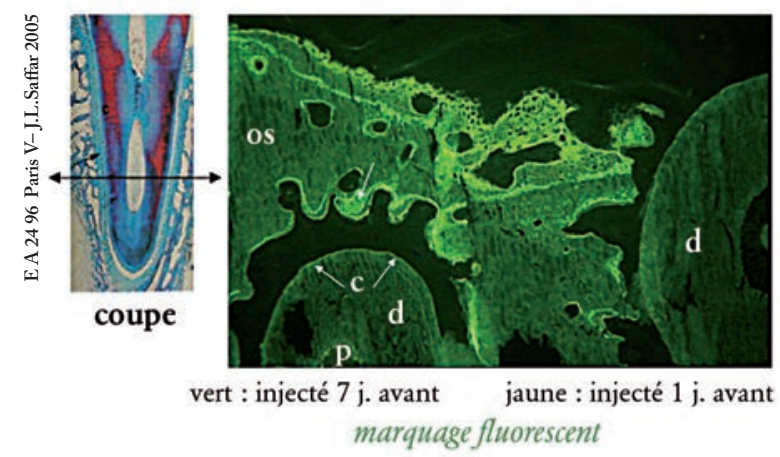

$\Delta$ Fig. 19.

Après différenciation des ostéoblastes et des cémentoblastes : remaniements osseux et cémentaire (élaboration tissulaire des CSM ) lors d'un déplacement physiologique.

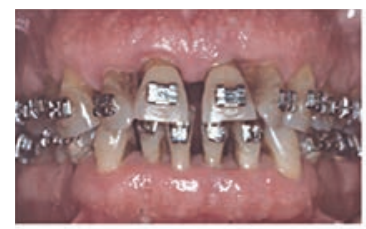

4 Fig. 21.

Migrations dentaires et articulation dento-dentaire perturbée. Après intervention parodontale, préparation pour le nivellement orthodontique mandibulaire.
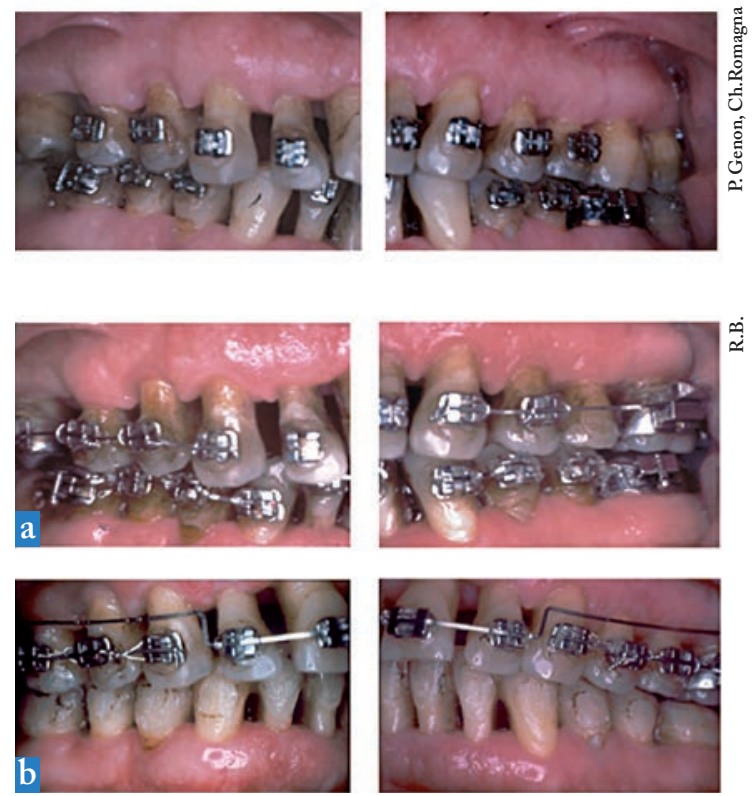

$\Delta$ Fig. 22.

a. Réglage et stabilisation des plans masticatoires.

b. Contention mandibulaire et ajustement des rapports antérieurs.
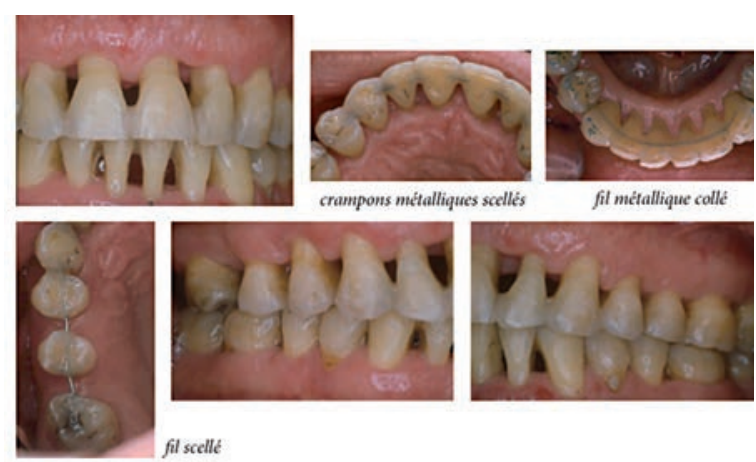

$\Delta$ Fig. 23.

Fin de traitement et contention. 
contrôlées cliniquement et par un statut radiographique (fig. 24, 25). Sur ces mêmes radiographies, la régénération de l'os alvéolaire est contrôlée au niveau de la molaire inférieure droite manifestant l'activité des cellules souches (fig. 26).

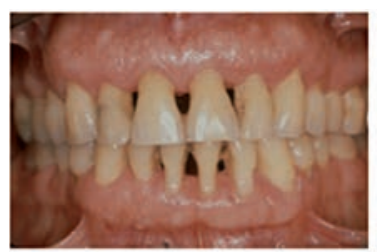

$<$ Fig. 24.

Parodonte superficiel après 15 ans.
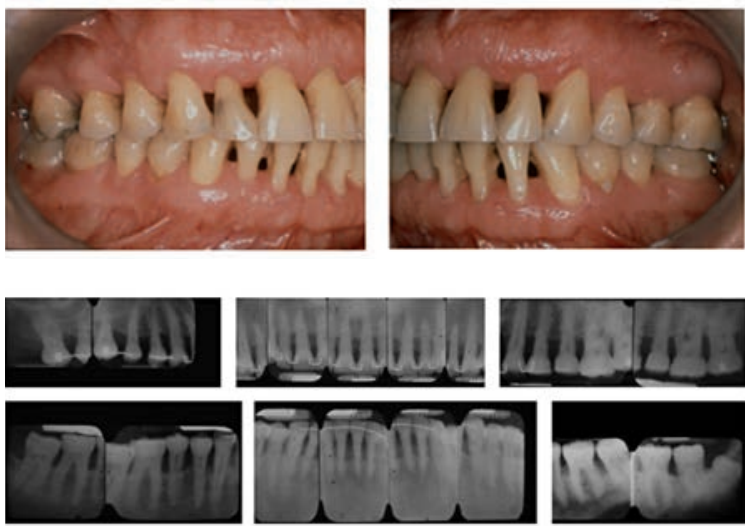

A Fig. 25.

Parodonte profond après 15 ans.

Cellules souches CSM : pluripotentes
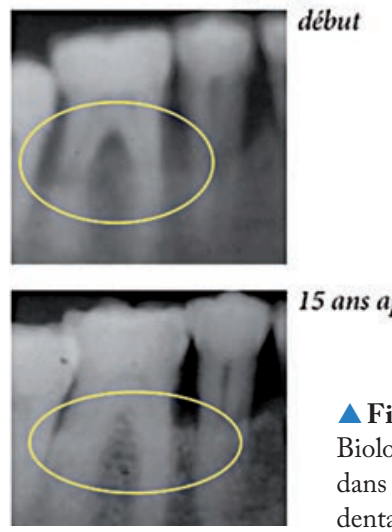

15 ans après

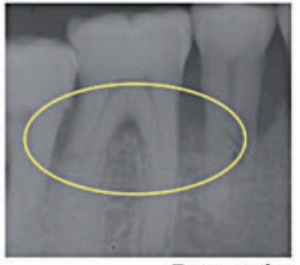

Fin tt ortho

$\Delta$ Fig. 26.

Biologie régénératrice de l'os alvéolaire dans les furcations et les espaces interdentaires.

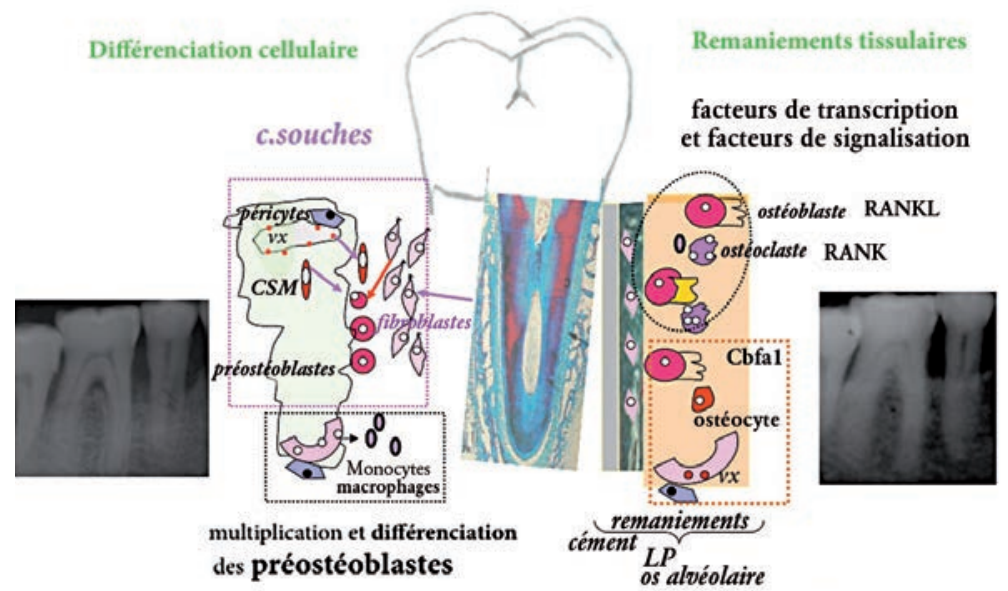

Début
15 ans après

$\Delta$ Fig. 27.

Biologie régénératrice : mécanisme.

\section{BIOLOGIE RÉGÉNÉRATRICE DU TISSU OSSEUX : MÉCANISMES}

Les cellules souches mésenchymateuses, si elles renouvellent les cellules rouges, blanches, les plaquettes, peuvent aussi se spécialiser pour la fabrication des monocytes puis des macrophages. Lors de forces orthodontiques (conditions environnementales), la libération d'une molécule MCSF (macrophage colony stimulating factor) oriente les cellules souches vers la différenciation de macrophages.

Dans une autre phase, après multiplication cellulaire, se différencient en grand nombre les ostéoblastes et les ostéoclastes. Sous contrôle de MSX2, les ostéoblastes expriment le ligand RANKL, alors que les ostéoclastes mettent en place le récepteur RANK. Les interactions entre RANKL et le récepteur RANK jouent un rôle déterminant dans la différenciation de ces deux groupes cellulaires et dans leur activation. Ce système est sous la dépendance de OPG (ostéoprotégérine) qui est un puissant inhibiteur de la résorption osseuse. En effet, OPG est un inhibiteur de la fixation de RANKL sur RANK. Cela se traduit par un défaut d'activité des ostéoclastes.

Finalement, dans une phase de construction, le facteur de transcription Runx2(Cbfa1) active la différenciation de nouveaux ostéoblastes qui élaborent une matrice extracellulaire progressivement minéralisée [4, 6] (fig. 26, 27).

\section{CELLULES SOUCHES ET INGÉNIERIE TISSULAIRE OSSEUSE}

Reconstruire un os humain en laboratoire est aujourd'hui possible en associant des biomatériaux de type organique ou inorganique avec des cellules souches capables de se différencier en ostéoblastes. Le génie cellulaire a permis de choisir les cellules souches les plus performantes. Ce sont celles matures qui proviennent de la moelle osseuse : les cellules souches mésenchymateuses (CSM). Les interactions entre les cellules souches et leur environnement peuvent bénéficier de facteurs de signalisation comme les BMP (Bone Morphogenetic Protein) [21].

Pour assurer encore une meilleure différenciation des cellules souches dans les biomatériaux, des chercheurs et des cliniciens expérimentent, in vitro et in vivo, chez le mouton, l'introduction d'autres cellules souches d'origine endothéliale pour une angiogenèse susceptible de créer un réseau vasculaire permettant pour la suite la nutrition du tissu osseux néoformé. Dans la sphère oro-faciale, les objectifs de médecine régénératrice, par ces moyens, sont : 
Iles reconstructions des mâchoires accidentées ou irradiées ;

Ile traitement des fentes faciales où les pertes de substance osseuses sont importantes ;

1 l'apport d'os alvéolaire nécessaire à la pose d'implants [7].

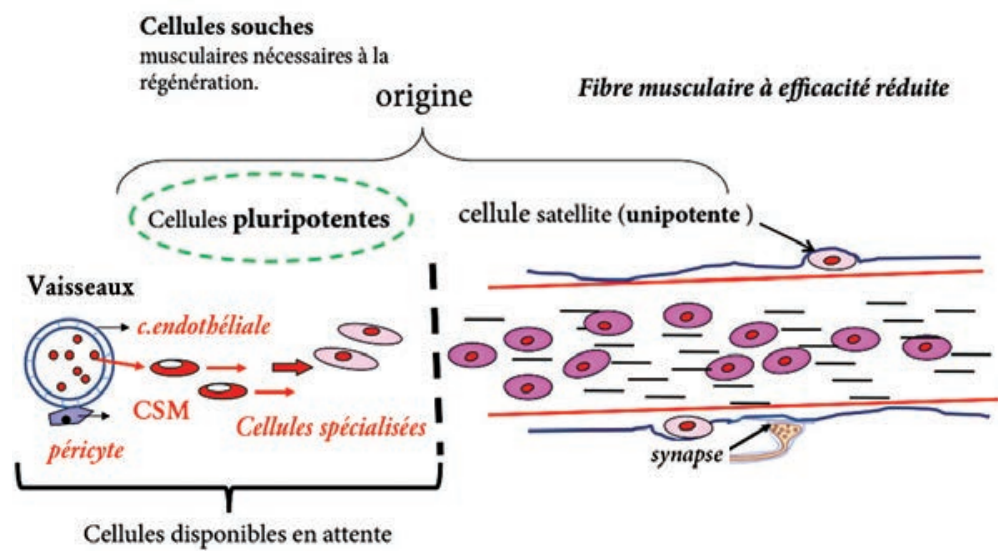

$\Delta$ Fig. 28.

Biologie musculaire. Il existe une corrélation entre le bon positionnement des noyaux dans les fibres et la fonction musculaire. Dans la fibre musculaire à activité réduite, les noyaux sont en position centrale.
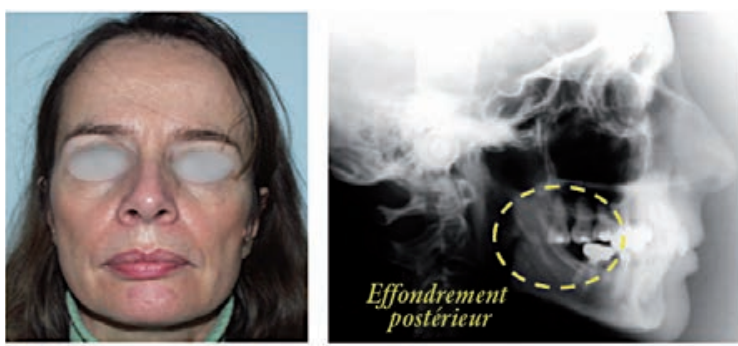

50 ans
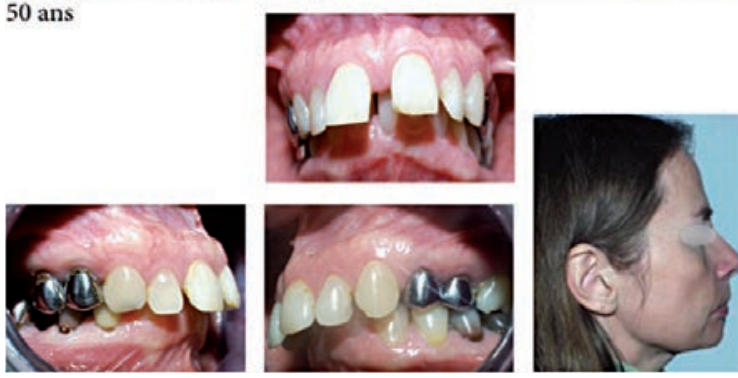

Fig. 29.

État des structures sous jacentes (dents et mâchoires) avant d'assurer la position des muscles faciaux, labiaux et leurs fonctions.
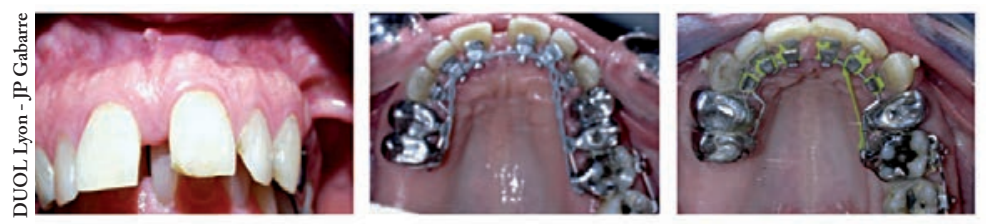

$\Delta$ Fig. 30

Technique orthodontique chez l'adulte.

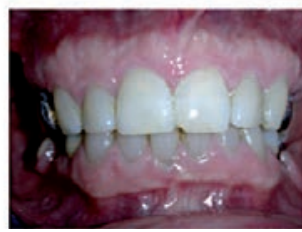

CELLULES SOUCHES ET BIOLOGIE RÉGÉNÉRATRICE MUSCULAIRE FACIALE

Les muscles masticateurs et faciaux de l'adulte sont composés entre autres de fibres plurinuclées possédant des propriétés contractiles. À ces fibres, sont associées des cellules appelées cellules satellites [19]. La plupart du temps, ces cellules sont quiescentes, se localisent entre la lame basale et le sarcolemme des fibres musculaires (fig. 28). Ces cellules sont activées à la suite d'une blessure, d'un effort intense ou au cours de myopathie [5]. Elles se différencient uniquement en fibres musculaires réparatrices. Elles sont dites unipotentes [22].

Il existe d'autres sources de cellules musculaires progénitrices. Dans ce tissu, on trouve un pool de cellules de réserve appelées cellules souches pluripotentes $[16,17]$ :

$\checkmark$ les péricytes situés à proximité des vaisseaux peuvent être mobilisés dans la circulation sanguine et après migration, être la source de cellules souches pour promouvoir l'angiogenèse et/ou la myogenèse ;

I les cellules endothéliales des petits capillaires sanguins interagissent avec l'environnement et sous influence du facteur de signalisation VEGF (vascular endothelial growth factor) peuvent stimuler l'angiogenèse et/ou la myogenèse. Ces différentes interactions participent à l'homéostasie musculaire ; $\checkmark$ les cellules souches mésenchymateuses (CSM), déjà citées au niveau du tissu osseux, sont présentes dans le tissu musculaire. Ces cellules pluripotentes appartiennent à une population cellulaire initialement identifiée dans la moelle osseuse. Ces cellules souches mésenchymateuses sont capables de migrer au gré des besoins des différents organes et d'exprimer leur potentiel régénérateur à distance de leur site d'origine (fig. 28).

\section{CAS CLINIQUE}

Après la mise en œuvre d'une hygiène buccale chez cette patiente de 50 ans, les structures parodontales et dentaires sont remises en état. Les examens complémentaires permettent de s'assurer de la position correcte des bases osseuses maxillaires et mandibulaires. Cette situation normale permettra de mettre en place des relations correctes entre les arcades dentaires et plus particulièrement de positionner le secteur antérieur incisivo-canin afin de donner des appuis normalisés nécessaires à leur fonction et à celle des muscles labiaux et faciaux. Après un an de traitement, les fonctions de mastication et de déglutition sont rétablies (fig. 29, 30, 31). La vascularisation s'intensifie 


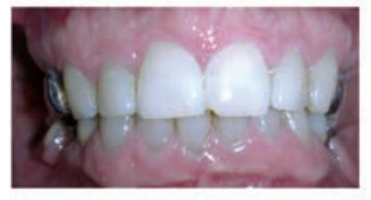

4 Fig. 31.

Fonctions : prothèses provisoires pour mastication-déglutition.
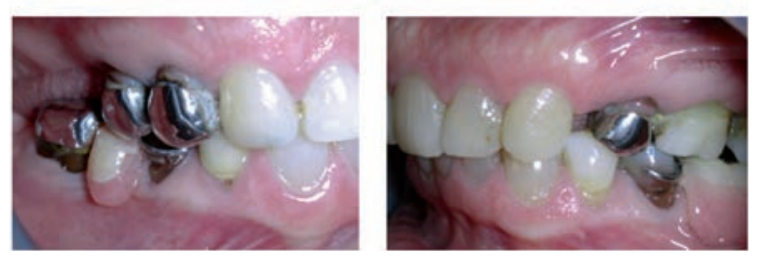

$\nabla$ Fig. 32.

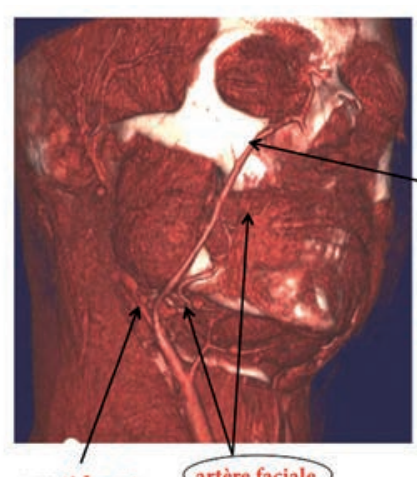

Vascularisation et muscles.

carotide ext. artère faciale

$$
\text { carotide ext. } \longrightarrow \begin{aligned}
& \text { VEGF: facteur de croissance } \\
& \text { pour linstallation de la vascularisation }
\end{aligned}
$$

Temps : 0

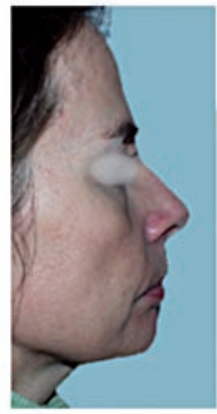

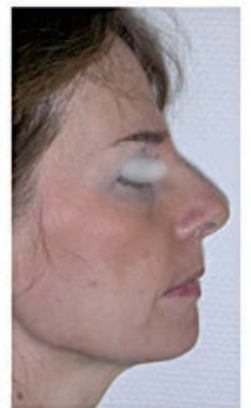

10 mois : vascularisation

\section{$\triangle$ Fig. 33 .}

Les muscles masticateurs, le buccinateur, les muscles labiaux sont fonctionnels et la vascularisation augmente dans les muscles masticateurs et faciaux. à l'aide de cellules souches: CSM, des cellules provenant des péricytes et des cellules endothéliales sous la signalisation de VEGF (fig. 32,33). Progressivement, la récupération neuromusculaire, facilitée par les facteurs de signalisation NGF et BDNF [8] (fig. 34, 35), permet de parfaire les fonctions de mastication, de déglutition et d'expression faciale.

\section{MÉCANISMES}

Au niveau des muscles masticateurs et faciaux, les fonctions sont essentielles pour obtenir des protéines régénératrices. Après l'augmentation des forces musculaires masticatrices ainsi que leur coordination avec celles de la déglutition et de l'expression, ces forces accélèrent le débit sanguin. Les cellules souches (cellules endothéliales, péricytes, CSM) se trouvent sollicitées, véhiculées, disponibles pour se différencier en de nombreux myoblastes, myotubes et myofibres. Ces dernières peuvent alors élaborer, sous signalisation génétique, de nouvelles protéines dont l'actine et la myosine [5] (fig. 36).
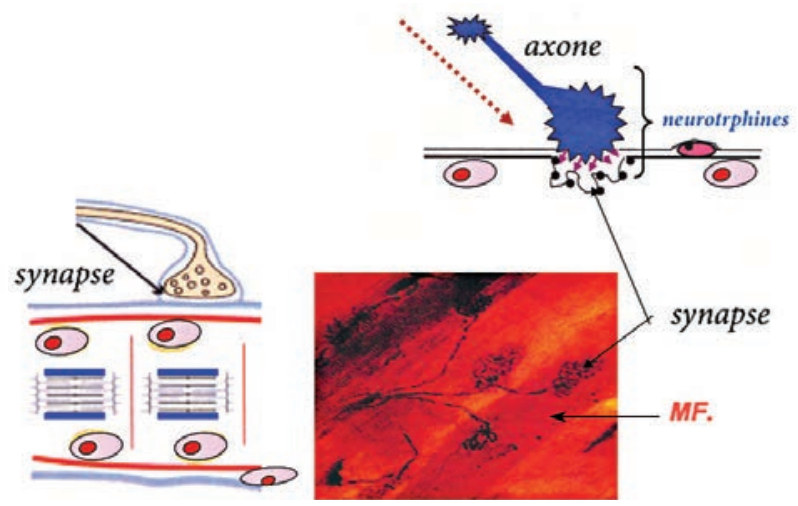

$\Delta$ Fig. 34.

Innervation. Facteurs de croissance : NGF, BDNF.

À lâge adulte, BDNF est impliqué dans les processus de plasticité neuronale et synaptique, mais aussi dans la neuro-transmission.
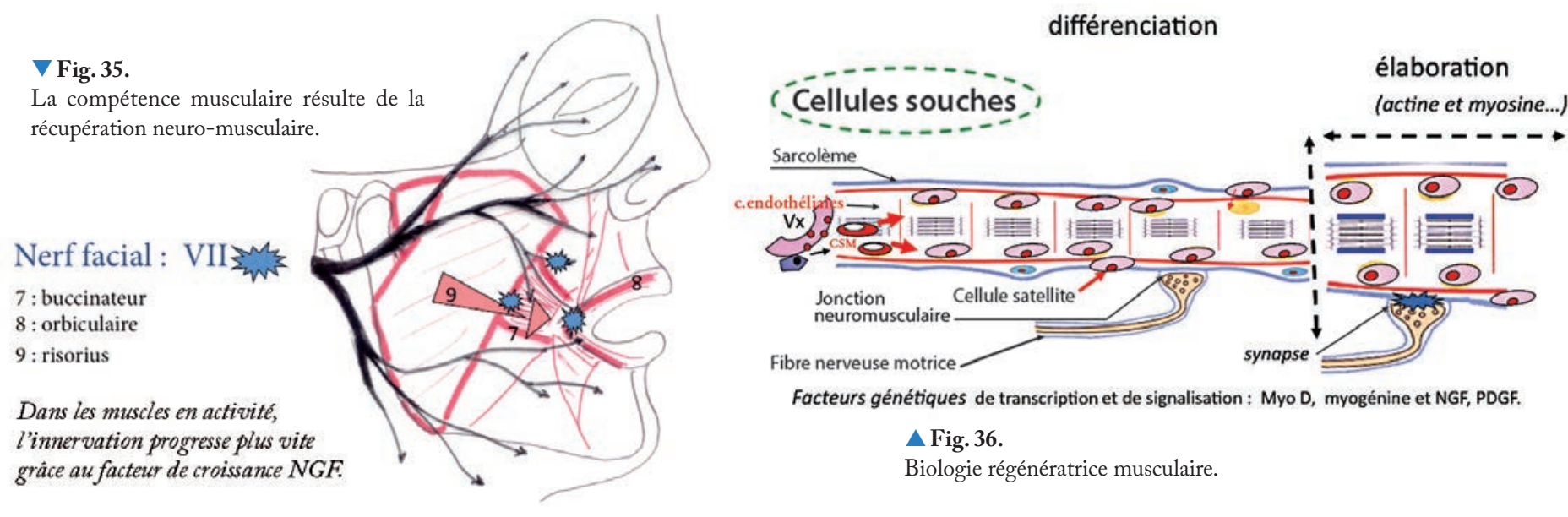

Facteurs génétiques de transcription et de signalisation: Myo D, myogénine et NGF, PDGF.

$\Delta$ Fig. 36.

Biologie régénératrice musculaire. 


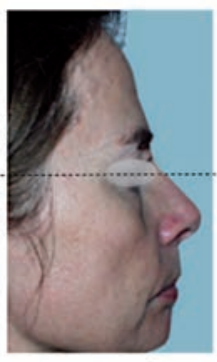

temps : 0

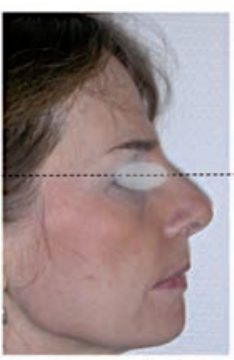

10 mois : vascularisation

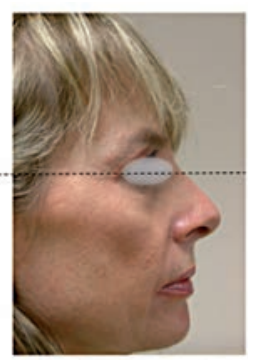

16 mois : innervation

$\Delta$ Fig. 37.

Récupération des fonctions et esthétique.

La vascularisation puis l'innervation réinstallées permettent la fonction faciale, labiale et rétablissent l'expression et l'esthétique (fig. 37, 38, 39).

\section{CONCLUSION}

Aujourd'hui après la mise en évidence de nombreux pools de cellules souches dans les tissus oro-faciaux, le clinicien est appelé dès maintenant à utiliser ce potentiel régénérateur.

En attendant la confirmation des recherches, en laboratoire, des potentialités des cellules souches pour une application thérapeutique, in vivo, le praticien peut avec discernement utiliser celles qui sont déjà à sa disposition dans les tissus où il veut intervenir pour les régénérer.

Les tissus gingivaux et osseux sont particulièrement riches en cellules souches pluripotentes. Dans ces diverses situations, il faut particulièrement avoir comme objectif le rétablissement des fonctions de protection et de mastication car les forces développées sont

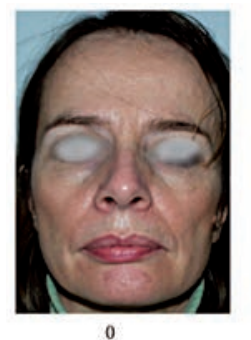

$\Delta$ Fig. 38.

Récupération des structures et des fonctions.

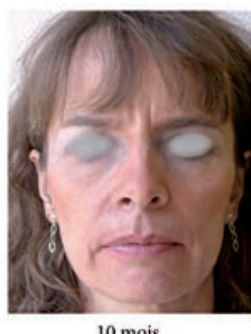

10 mois

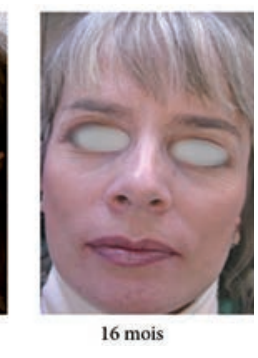

16 mois
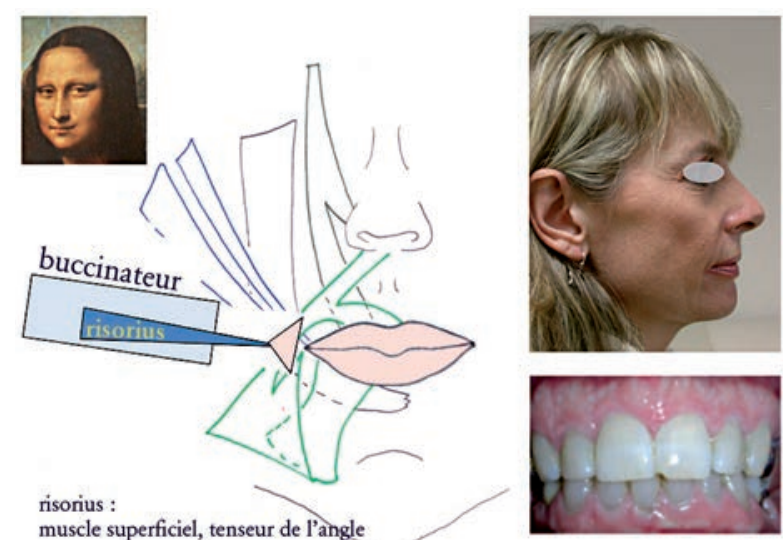

A Fig. 39.

Esthétique, «fonction d'expression ».

nécessaires à la différenciation de cellules souches spécifiques. Cet objectif est surtout impératif pour le tissu musculaire où la vascularisation est augmentée et essentielle dans l'apport des cellules régénératrices. À présent, l'utilisation de toutes les nouvelles techniques et informations scientifiques qui nous sont proposées est nécessaire à l'application de nos missions de Thérapeutique et de Recherche.

\section{Bibliographie}

[1] Abad M, Serrano M. Des cellules souches au super pouvoir. Science et médecine. Le Monde, 18 septembre 2013.

[2] Bartold PM. Periodontal tissues in health and diseases introduction. Periodontoloy 2006;40(7):10.

[3] Bencherif S.A. et al. Force de traction à l'interface cellule-matrice extracellulaire et destin des cellules souches mésenchymateuses $M / S$ 2011;1(27):19-21.

[4] Benoît R, Granat J. La canine dans le système alvéolo-dentaire. ODF 2010;44:17-45.

[5] Benoît R. De la face au visage. À travers l'art et la biologie du développement normal et pathologique. Edit. R. Benoit, 258 p, 2012.
[6] Bragard E. Cellules souches et parodonte. Univ. Cl. Bernard Lyon 1, Thèse Doct. Ch. Dent. 102 p, 2009.

[7] Castros S, Guillemot F, Amedee J, Frican FC. Bone tissue engineering in oral and maxillofacial surgery: clinical applications. Med Buccale 2010;16:227-237.

[8] Charoy G, Castellani U. Le facteur de survie neuronale GDNF, $M / S$ 2013;2(29):127-130.

[9] Fournier B, et al. Multipotent progenitor cells in gingival connective tissue. Tissue Engineering 2010;1-29.

[10] Fournier BP, Larjava H, Häkkinen

L. Gingiva as a source of stem cells with therapeutic potential. Stem Cells Dev 22(24): 3157-77.
[11] Gogly B, Ferre FC, Cherifi H, Naveau A., Fournier B. Inhibition of elastin and collagen networks degradation in human skin by gingival fibroblas in vitre, ex vivo and in vivo studies. $J$ of Cosmetics, Dermatological Sciences and Application 2011:1: 4-14.

[12] Hacking SA, Khademhossei NA. Applications of microscale technologies of regenerative dentistry. J Dental Res 2009;88(5):409-421.

[13] Hayashi $Y$, et al. Comprehensive analysis of gene expression in the jonctionnal epithelium by laser microdissection and microarray analysis. $J$ Periodontal Res 2010;45:618-625.

[14] Jorgensen Ch, Deschaseau F, PlanatBernard V, Gabison E. Les cellules souches mésenchymateuses. Actualités thérapeutiques $M / S$ 2011;3(27). 


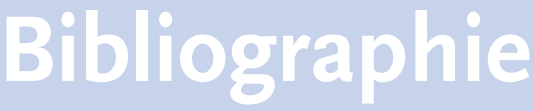

[15] Kerkis I, et al. L'isolement et la caractérisation d'une population de cellules souches de la pulpe dentaire exprimant OCT-4 et d'autres marqueurs de cellules souches embryonnaires. Cellules des tissus, des organes 2006;184 (3-4)105-106.

[16] Khalil RA, Patridge T, Chazaud B. Les cellules du muscle chantent en cœur une berceuse pour cellules souches $M / S$ 2010;6-7(26) : 589-591.

[17] Le Douarin L. Les cellules souches porteuses d'immortalité. Paris : Odile Jacob édit. 410 p., 2007.
[18] Ma L, et al. (2012) Cryopreserved dental pulp tissues of exfoliated decideous teeth is a feaible stem cell ressource for regenerative medecine. Plos One 2012;7:1-26.

[19] Mayeuf A, Relaix F. La voie NOTCH. Du développement à la régénération du muscle squelettique. $M / S$ 2011;5(27):521-226.

[20] Mura M, et al. Dépôt : cellules souches de dents de lait exfoliées humaines. Proc Nat Acad Sci USA $2003 ; 100$.

[21] Myon L, Ferri J, Chai F, Blanchemain $\mathrm{N}$, Raoul G. Ingénierie du tissu ossueux oromaxillo-facial par combinaison : biomatériaux, cellules souches, thérapie génique. Rev de Stomatologie et de chirurgie maxillo-faciale 2011;06, 002 .
[22] Nanceau M, Marcelle Ch, Gros J. Une source unique de progéniteurs musculaires $M / S$ 2005;11(21):915-917.

[23] Nakov S. Cellules souches de la pulpe dentaire : différentiation, signalisation et réparation, Thèse de doctorat en biologie cellulaire, Paris V, 2012.

[24] Seo BM, et al. Investigation of multipotent postnatal stem cells from human peridontal ligament. Lancet 2004;364(9429):149-55

[25] Yamanaka S. Des cellules souches. Science et médecine. Le Monde, 18 septembre 2013.

[26] Zivkovic P, Petrovic V, Najman S, Stefanovic V. Stem cell-based dental tissue engineering. Scientific World J 2010;10:901-916.

\section{Librairie Garancière}

\section{Commandez rapidement vos ouvrages sur Internet}

- Paiement sécurisé en ligne

- Prise en compte de votre commande le jour même

\section{www.librairie-garanciere.com}

